\title{
MOTIVATION AND STIMULATION MECHANISM OF MEDICAL STAFF IN DEVELOPING COUNTRIES: MAIN CHALLENGES AND WAYS OF ITS IMPROVING IN UKRAINE
}

\author{
Viktoriia Borshch ${ }^{1}$, Roman Shchur ${ }^{2}$, Oleg Chuvakov ${ }^{3}$
}

\begin{abstract}
The main purpose of the article is to propose the effective instruments of motivation and stimulation of the medical staff within the modern Healthcare Reform in Ukraine. In the article, the main problems and challenges of the stimulation and motivation process of the medical personnel in Ukraine are viewed. The theoretical basis of the motivation process is considered. This article analyses the approach of the differentiation of the "stimulation" and "motivation" categories. The point is stressed that motivation's main goal is a state change in the medical organization from the point of view of personnel management, and the stimulation is directed to confirming this state. So these two processes are the part of one strategic mechanism of the personnel management and should complement each other. The current situation in the labour market of the healthcare sector is examined. The main issues of this market are defined. And on the basis of the specified problems, the instruments and methods of stimulation of medical staff are proposed by the author. The system of grids as the part of the financial and monetary incentives at the medical establishment is offered with the purpose of its medical staff's activity improvement. The practical importance of the scientific research results lies in detailing the motivation and stimulation process and its detailed analysis from the point of view of the healthcare sector, which is important for the further development of the healthcare sphere in Ukraine. Methodology. The methodological basis of the article is the complex of methods, including methods of scientific cognition, analysis and synthesis, systematization and scientific abstraction. The informational basis of the conducted research is the scientific works of the domestic and foreign scientists in the sphere of management and organization of health care, the statistical data of the State Statistics Service of Ukraine, legal and regulatory documents of the Ministry of Health of Ukraine. Results. The proposed mechanism of medical staff's motivation and stimulation allows solving the problems related to the shortage of the medical staff, the quality of their activity and their performance improvement etc. Further research directions are aimed at the study of all aspects of managerial capital formation and improvement in the healthcare field.
\end{abstract}

Key words: stimulation, motivation, medical staff, remuneration of medical staff, system of grids, health care system, medical reform.

JEL Classification: J33, 118

\section{Introduction}

The reformation of the healthcare sector has been taking place in Ukraine for more than 20 years. In the beginning, this reform was based on the implementation of a new economic mechanism, based on the model of insurance medicine. Unfortunately, one of the main goals of medical reform - economic interests of the medical staff for the results of their activity - still has not be realized fully. And without a solution to this problem,

Corresponding author:

${ }^{1}$ Odessa I.I. Mechnikov National University, Ukraine.

E-mail: viktoriyaborshch@gmail.com

ORCID: https://orcid.org/0000-0001-9106-9078

${ }^{2}$ Vasyl Stefanyk Precarpathian National University, Ukraine.

E-mail: romanwur@ukr.net

ORCID: https://orcid.org/0000-0001-9945-3939

${ }^{3}$ Odesa I.I. Mechnikov National University, Ukraine.

E-mail: anyuta@te.net.ua

ORCID: https://orcid.org/0000-0001-9983-8943 even while using the goal-based method of planning and sufficient healthcare funding, it is impossible to reach the target figures of effectiveness and performance of the sector. Since the mid of 2017 the medical reform has got the new vector, consisted in the implementation of the medical institutions' autonomization and 'money goes for the patient" principles. Such principles should finally decide the problem of the physicians' remuneration but not all the staff of the medical institution. 
Medical staff and, first of all, physicians, is the main resource of the health facility. It is they who provide the performance of the medical institutions' activity. However, it is possible only in the conditions of the evidence-based system of labour stimulation and motivation, which has very low development level in Ukraine. Unfortunately, the modern medical reform still has not proposed the adequate mechanism of payroll formation and has not recommended the instruments of the optimal motivation and stimulation of the medical staff's activity.

In that regard, study of the motivation instruments, identification of the motivational factors, formation of the effective model of stimulation, analysis of working conditions of physicians, and search for the best methods of motivation in the system of remuneration is the most actual while studying the issues of improving the provision of health care to the community.

The goal of this article is to propose effective motivation and stimulation instruments of the medical personnel taking into account the current reformation of the healthcare sector.

Methodology. Such scientific methods, as analysis, synthesis, compilation, and scientific evidence, were used during the research. The scientific works of domestic and foreign scientists in the sphere of healthcare management and organization, statistical data of the State Statistics Service of Ukraine, legal and regulatory documents of Ministry of Health of Ukraine were used as the informational basis for the conducted research.

\section{The main challenges of the personnel management of health care system in Ukraine}

Current situation of the personnel management of the healthcare sector in Ukraine is characterized by two significant problems:

I. The remuneration of the social workers in Ukraine, including the medical staff, is low. Positive variation in wages has not been seen in recent years. The revised salary scale in the healthcare segment resulting from the survey is $60-70 \%$ lower than industrial one, and as of June 2018, the average wage in the healthcare sector is $3,720 \mathrm{UAH}$ or $\$ 142$ (in comparison with the average wage of physicians in the USA, which is about $\$ 150,000$ per year or $\$ 12,500$ per month, or with the average wage of physicians in the EU, which is about 80,000 euro per year). Such a situation exists because underfunding of payroll amounting to 16,000 million UAH takes place in Ukraine. As the source ("Zarplaty likariv", 2018) has claimed, the budget for the healthcare sector in Ukraine in general is about $113,923,655,500 \mathrm{UAH}$ (3,5\% of GDP of Ukraine), but in doing so the National system of health care should have the budget not less than 5\% of GDP for the proper functioning, on the recommendations of $\mathrm{WHO}$.
Thus, the wish of the medical staff to receive additional income from the patients could not disappear since there is not an adequate system of stimulation and motivation of their labour. Experience has shown that informal remuneration in Ukraine, into the hands of the medical staff, is widely disseminated in Ukrainian healthcare sector. Not only does this undermine physicians' image but, more ominously, it hurts household budgets.

The main reason for such informal payments' existence in the healthcare sector is the low level of remuneration of medical staff. In public health institutions in the sphere of medical services, there are not full economic relations. This led to that the domestic health administration was built and continues to be managed on the principles of the administrative model. Healthcare field's funding and the activity of the health treatment facilities are carried out on the basis of standards, which are defined for each medical institution by public administration bodies. In such conditions, there is no system of appraisement of labour results, motivation, and economic incentives.

The health care system works on the principles of hourly wage, which has several substantive shortcomings. The remuneration of the medical institutions is based on the single wage grid taking into account all copayments. Such a wage system is fixed, does not depends on the volume and quality of conducted activities. In accordance with an hourly wage, to the medical staff must be paid the wage, even if they have not carried out the certain scope of work. Imagine the situation. Two physicians with the same experience and qualification work in the same conditions. One physician is highly qualified, to whom there are about 30-30 appointments of the patients per day. And the other one does not work hard, he has about $10-15$ patients per day. In accordance with the single wage grid, both of them receive the same wage. Eventually, the first physician will rebuild new behaviour that it is not necessary to overstress at work because it won't change his remuneration. That is, in the above-shown situation one of the most important functions of remuneration system - stimulation - does not work, so the employer does not have the possibility either to encourage or to sanction his/her employees. Consequently, the quality of the medical assistance declines because the wish to give greater efforts to the treatment process disappears.

II. There is the significant shortage of specialists at the primary, secondary, and tertiary levels of the healthcare sector. In this, the specialists staffing is disproportionate at the rural and urban districts.

Thus, in the regional centres, where is the medical high schools, the rate of the staff capacity and staffing rate accounts for about $90-100 \%$.

In the cities, where there is no medical school, the rate of medical specialists in the central district hospitals, accounts for about 70-90\%. However, the stuffing problem is solved there by the way of the holding by specialists of several positions. The shortage 
of endocrinologists, anaesthetists, paediatricians, radiologists, infectious disease specialists, tuberculosis specialists, pathologists, ophthalmologists, urologists, and other physicians is the common situation for the regions, where there are no medical schools.

In rural areas, the stuffing problem is more sufficient. The rate of medical specialists of general practice and other specialists is less than $70 \%$.

Generally in Ukraine at the secondary level, there is the lack of medical personnel of about $10 \%$ of specialists of different directions; at the primary level, the lack is about $30 \%$ of general specialists.

In this, there is the significant share of medical staff, namely physicians, of retirement age. In some regions of Ukraine, their rate accounts about $40 \%$ of total staff. For example, according to the approximate calculations, in Vinnytsia region, there are $28 \%$ of the physicians of retirement age at the primary level, $23 \%$ on the secondary level, and $19 \%$ at the tertiary level. And most of the staff is the people more than 65 .

Such a process of ageing of the staff influences the quality and speed of the medical services provision that is characterized by the use of the outdated methodology, algorithms of medical services provision and technologies, lack of the interest to get new knowledge and to develop, so on.

The main reasons for the shortage of specialists in the healthcare sector are the following:

1) disproportionality and inadequacy of the medical staff's wage level in comparison with the volume and quality of provided medical assistance, on the one hand, and on the other, in accordance with the specialists from the industrial and other spheres of the economy;

2) the lack of state support for young specialists in the healthcare sphere;

3) insufficient financial support for rural health care;

4) low level of the material and technical and regulatory bases of the medical institutions;

5) undeveloped infrastructure generally all over the country;

6) bad social and living conditions of the medical staff (for example, lack of accommodation) and lack of state interventions for their improvement;

7) problems with the professional development of the medical staff;

8) ageing of the medical staff, i.e. the specialists of retirement age hold the posts, which could get the young physicians;

9) travel abroad of the specialists for work (the most intensive dynamics is directly after the graduation from the higher education institution).

So we see that the problem of staffing of medical institutions, the formation of adequate payroll and effective system of the motivation and stimulation of medical personnel are the thorny issue. And the medical reform, conducted nowadays in Ukraine, confirms inability of the system to move to the European standards of medical assistance providing and healthcare administration, and even the problem of the shortage of the personnel worsen while this reform has been conducted. Before the beginning of the reformation, staffing of the medical institutions was bloated, because stuffing structure was regulated by the norms in accordance with the number of population. As provided for by the current reform, from 2020 the secondary and tertiary levels of healthcare will be financed according to the volume of actually provided medical services. That's why it's highly probable that the staff of medical institutions of these levels will be significantly reduced because the transition to the market relationships will lead to the specialists' cuts or their reassignment.

Problems mentioned above are very painful for the Ukrainian healthcare system and, first of all, are caused by the lack of adequate personnel policy in the healthcare field. That's why it's quite natural that the stagnation of this economic field and social welfare area is going on.

The medical establishment, like any other enterprise, could bear significant losses because of inefficient wage bill administration, and labour productivity could reduce because of the unfair or non-transparent system of compensations and incentives. Thus, all abovementioned problems cause the necessity of implementation of mechanisms of medical staff's motivation and stimulation.

\section{The theoretical basis for the effective mechanism of motivation and stimulation of medical staff creation}

Formation of the effective mechanism of staff's motivation and stimulation is one of the main functions of any manager since it influences the organization's personnel in order to increase their activity, effectiveness, and productivity.

It is important to define correctly categories of motivation and stimulation since these categories are interchangeable, but vice versa, they complement each other.

In the scientific literature, motivation is defined as a process of deliberate choice by a person of a certain type of behaviour, which is defined by the influence of the external (incentive) and internal (motive) factors. In the course of employment, motivation allows the employees to meet their basic needs by means of completing their working duties.

Motivation process is presented schematically in Figure 1.

From the model, presented in Figure 1, we can see that the motivation of the labour activity is conducted on the basis of the needs. Thus, taking into account the needs of their subordinates, managers have to encourage them to the actions in order to achieve the goals. In this, individual and corporate goals must be subordinated. 


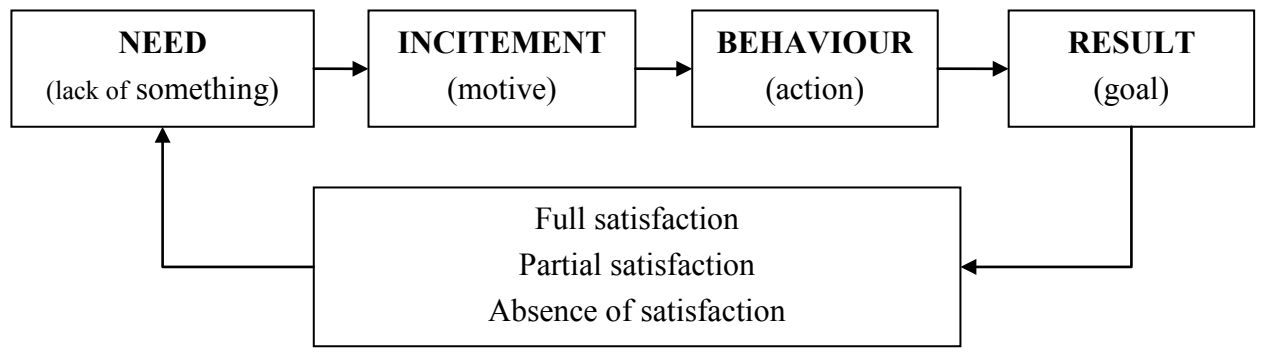

Figure 1. A simple model of the motivation process

Source: (Mescon, Albert, Khedouri, 1998)

So, in accordance with generally accepted in management theory and practice model of motivation, the workflow and the motivation mechanism must be built individually for each employee, taking into account the true motives of employees' behaviour.

Motivation process must be supported by the instruments of stimulation (remuneration). Motivation and stimulation should be always in a buddle to create the inefficient mechanism of motivation and stimulation.

In the scientific literature, stimulation is defined as the external encouragement to the actions that are rooted in the interest (material; moral, emotional, individual or group).

Internal remuneration (by which is meant motivation) is given by the work. It could be the feeling of satisfaction by the results, content or importance of the work, selfrespect, and so on. Thus, the easiest way of providing internal remuneration is to create appropriate work conditions and correct formulation of objectives. At the medical establishment, the example of such instruments is the creation of appropriate working conditions due to ensuring the material and technical equipment (i.e., in accordance with indicative sheet of material and technical equipment of medical establishments, the Order of Ministry of Health of Ukraine № 148 dated 26th of January 2018), computerization, adequate vocational education and development of the medical staff, rotation, etc.

Inner remuneration appears not from the work but is given by the organization. From the motivation point of view, it could be defined as work stimulation and is directed to the full realization of the existing labour potential.

Thus, on the basis of aforesaid, motivation and stimulation translate the strategy and tactics of personnel management. Motivation is the strategic line, directed on the achieving global goals, set before the employees and are coupled with corporate goals. For example, a physician seeking to rotation or enhancement of vocational knowledge by at the cost of the medical establishment, in which he works, contributes to its development due to received knowledge and skills. Stimulation is the tactics in the motivation mechanism, which meets certain motives of employees (mostly, material) and allows increasing the labour productivity (i.e., encouragement by awards, premiums, bonuses, thirteenth-month bonus, bonus for overtime, flexible schedule and so on.

Thus, we see that motivation and stimulation are opposite in their directions: motivation is aimed at changing the current state at the organization, and stimulation is directed to its confirming, however, they complement each other.

Thus, for example, two medical institutions with similar working conditions use only one abovementioned instrument: the first one uses just the motivation mechanism (ensuring the required material and technical facilities, computer software of the working process, flexible work schedule, preventive medical examination of the staff, and the assessment of the workplaces), and the other one uses only stimulation (salary increases for the hard labour conditions, bonuses for overtime work, payments for the health resort at the costs of medical establishment). In the first case, measures that are used by the medical establishment are directed to improve working conditions and contribute to creating new working conditions. In the second case, the measures entrench the current situation in the medical establishment by detention personnel in it by means of material encouragement. But nevertheless, at any time in the same conditions the high staff turnover could appear in these health institutions since such processes do not take into account the interests of all categories of the personnel, they represent the separate elements of the motivation process. And for the solution of the problem of improvement of the medical services' quality and the effectiveness of their providing, it is necessary to use an integrated approach, which considers the existence of the following types of employees:

1) employees who are focused on the content and social importance of the work;

2) employees who are focused on the labour remuneration and other material assets;

3 ) employees who have the balance of different values. 


\section{The system of grades in the healthcare sector}

We have to propose the system of grades as the most optimal system of remuneration. Its goal is the integration of the level of responsibility, the uniqueness of the experience, knowledge and skills, results of activity of each representative of the medical staff. Such a remuneration system allows unifying appropriately the motivation and stimulation instruments and building the universal job hierarchy, based on flexible levels of salaries in accordance with the volume of conducted works and provided services by the medical staff, with their internal needs, skills, and knowledge.

Thus, grading is a grouping of the positions for specific principles with a purpose of work standardization in the organization.

The main idea of this method is the creation of the basis for the effective managerial decision-making process concerning: (1) the employees' salaries; (2) employment benefits; (3) bonuses and extra-payments. In this, the main advantages of this method's implementation are the principle of transparency of prospects for the medical establishment's employees: the employee understands, what he/she must do, over what period, that his/her salary will increase ("Zarplaty v medychnii haluzi”, 2014). So, the grading allows the employees to overview the possibility of changes in the salaries' level while different career moves. For the governing body of the medical enterprise, it helps to decide about wage indexation and defining of the level of the extra-payments for new positions. For the personnel service of the medical establishment, it allows simplifying the administration of the system of the financial incentives. Such a remuneration method allows encouraging the employees to the highly productive work.

Grading system evaluates the activities, which are conducted at each position in the establishment, on the basis of three groups of factors:

1) knowledge, qualification, and experience, which is necessary for the works execution (i.e., practical procedures, use of up-to-date algorithms, technologies and protocols of medical assistance provision, special methods and approaches, vocational knowledge, communicational skills);

2) skills, which are necessary for the problems' solution in the medical sphere and related to the ability for the analytical and critical thinking and implementation of the innovative technologies of medical assistance provision, the complexity of the provided medical services;

3 ) the level of responsibility, which includes the borders, within which medical staff at this position is able to make decisions individually, frameworks of activities and the level of the individual input into the outcomes of the medical establishments' activity and the quality of work.
Simplified grading methodology is the following: the position receives from the expert a certain amount of points by each factor, which is considered as the important and actual for the medical establishment. Multi-hazard assessment of the activity reflects the relative weight of each position. In accordance with a received point, the job positions are counted towards a certain grade, which guarantees the certain wages or employment benefits ("Zarplaty v medychnii haluzi", 2014).

It means that employees, who hold the same position, can receive the different salary. Depending on the grade, more will earn that physician, who has a particular experience, has attended the upgrading courses, got particular medical categories, abides the principle of patient-oriented activity, is able to work in the team, has a significant number of patients' appointments, and the quality of his medical services is high. The employees with the same grade (and the same salary) can occupy different positions, for example, cardiologist and the head of the department. So, the situation is possible, when the subordinate is at the same high grade, as the chief, and consequently, he will get the higher salary. It means that he is a unique specialist, who is valuable for the medical establishment.

The algorithm of the grading system implementation consists of the following stages:

1. Training of the working group.

2. Documentation maintainer (concept, standards, etc.).

3. Analysis of the activities' context.

4. Assessment of the positions (questionnaire, interviewing, etc.).

5. Definition of requirements for the positions and the clarification of the factors.

6. Definition of the weight of the reference works with the use of the certain method of assessment of the works' complexity.

7. Allocation of the factors by the levels (ranking).

8. Assessment of each level.

9. Assessment of the weight of each factor.

10. Calculation of the number of points for each position.

11. Allocation points by the grades.

12. Definition of salaries and calculation system of remuneration.

13. Analysis of the results and correction of the inconsistency.

Such a system explains the hierarchy of positions by the context of the activities. Each position of the structure defines the requirements for each position and allows the employees to define their subordination, the degree of responsibility, the need of development ("Zarplaty v medychnii haluzi", 2014).

Implementation of the grading system is necessary for the big and medium-sized medical institutions and organizations since it addresses shortcomings of the previous remuneration system of the single wage grid, 
such as bureaucracy, non-transparency of the inner logic of tariffs and grids construction, the rigidity of the hierarchical structure. Grading allows building flexibly the structure of the positions in the organization, taking into account not only the qualification and experience but also other very important factors, i.e. level of responsibility, level of works' complexity, quality of the conducted medical services, patients' satisfaction, etc. And for the medical staff, it gives the opportunity to understand, how their salary is formed, how can they change their salary, and what their career development will be.

\section{Conclusions}

From all of the foregoing, it is clear that there is a need for great changes in the process of the wage bill and motivation mechanism formation at the medical establishments. In our opinion, it is necessary partially to learn from the foreign experience of the developed healthcare systems, taking into account our realities and opportunities (financial, human, innovative, etc.). Thus, the essential are the following measures:

1) implementation of the measures to curb corruption at all level;

2) implementation of the system of the quality appraisement of the medical services provision and creation of the special service, which goal is to implement in good faith assessment and analysis of the effectiveness and quality of conducted medical services; 3 ) constant and continuous development of the medical staff on the transparent and rating conditions;

4) creation of the conditions for organization and implementation of incentives and motives for the medical staff's encouragement, whereby the salary of medical staff must depend on the level of qualification, their input into the outcomes of medical establishment, quality of the medical services, patients' satisfaction by the conducted medical services and medical aid;

5 ) increasing of the wage bill;

6) implementation of the wild system of the extrapayments and premiums (benefits for obtaining accommodation, free vacation, free upgrading. etc.);

7) improvement of the material and technical basis of the medical establishment, purchase of the modern equipment and innovative technologies with the purpose of the specialists' motivation;

8 ) formation of the system of financial and social support of young specialists.

The measures proposed below are not finite and it is not a panacea but, nevertheless, they must become a part of the state and local system of motivation with a purpose of the Ukrainian healthcare system development.

\section{References:}

Bidiuk, O. O. (2009). Systema hreidiv yak innovatsiina forma oplaty pratsi [A grid system as the innovative form of remuneration]. Retrieved from: http://www.rusnauka.com/8 DNI 2009/Economics/43228.doc.htm (in Ukrainian)

Medprosvita (2018). Zarplaty likariv, medsester ta sanitariv u 2018 rotsi ne zminiat [Salaries of the physicians, nurses and orderlies won't be changed]. Retrieved from: https://medprosvita.com.ua/zarplati-likariv-medsester-tasanitariv-u-2018-rotsi-ne/ (in Ukrainian)

Kamska, O., Berezkina, O. \& Shutkevytch, O. (2018). Yak utrymuvaty "kadrovyi holod"? [How "personnel shortage" must be hold?]. Vashe zdorovya - Your health, № 17-18 (1457-1458), pp. 16-19. (in Ukrainian)

Mescon, M. H., Albert, M. \& Khedouri, F. (1998). Osnovyi menedzhmenta [Fundamentals of Management]. Moscow: Case. (in Russian)

Ministry of Health of Ukraine (2014). Zarplaty v medychnii haluzi na 60-70\% nyzhchi, nizh v promyslovosti [Salaries in the medical sphere is by 60-70\% lower, than in productive sphere]. Retrieved from: http:/ www.moz.gov.ua/ua/ portal/pre_20141017_g.html (in Ukrainian) 